\title{
Epidemiological evidence for distinguishing subsites of colorectal cancer
}

\author{
JEAN FAIVRE, LAURENT BEDENNE, MARIE C BOUTRON, CHANTAL MILAN, \\ REMY COLLONGES, AND PATRICK ARVEUX \\ From the Registre des Tumeurs Digestive (INSERM SCN 17), Faculté de Médecine, Dijon, France.
}

ABSTRACT The registry of digestive tract tumours established for the department of Cote d'Or (France) was used to study the epidemiological characteristics of large bowel cancer subsites for the period 1976-1983. Age standardised incidence rates for colon cancers were 18.9/100 000 for men and $14 \cdot 2 / 100000$ for women. The corresponding rates for rectal cancers were 18.4/100 000 and $10 \cdot 2 / 100000$. The sex ratio for right colon cancer (caecum, ascending colon, hepatic flexure, transverse, splenic flexure) was close to 1 and did not change with advancing age, while that for the left colon (sigmoid, descending colon) showed a male excess after 65. For rectal cancer (rectosigmoid junction, rectal ampulla) the male predominance was more marked and occurred earlier, after 55 years of age. There was no significant variation in incidence between rural and urban areas for the different sublocalisations. In males the risk was high in the highest social classes for left colon cancer $(\mathrm{p}<0.01)$, and among farmers for rectal cancer $(\mathrm{p}<0.01)$. The risk of left colon cancer in males increased with the comfort of housing $(\mathrm{p}<0.01)$, but this marker of social class had little influence on incidence for the other localisations in males, or for any localisation in females. No significant variation was found with education. The incidence of colon cancer tended to increase over the 8 years of study. The variations were significant for left colon cancer. For rectal subsites cancer incidence decreased in women $(\mathrm{p}<0.05)$.

The observed differences suggest differences in the aetiological factors within large bowel cancers. Therefore right colon cancer, left colon cancer and rectal cancer should be considered separately in epidemiological analytical investigations.

Compilation of incidence data from cancer registries throughout the world has drawn attention to large bowel cancer. This cancer is one of the most frequent neoplasms in western countries, thus representing a major public health problem. Attempts at identifying the risk factors of the disease have produced disappointingly ambiguous results. Because of this disquieting situation the knowledge of descriptive epidemiological data has become very important. It represents a way of delineating risk groups. Relatively few population based reports have provided data on the epidemiological differences in cancer at various subsites of the large bowel. These reports have separately examined sex and age distribution, ${ }^{12}$ social factors, ${ }^{3-5}$ or time trends. ${ }^{6-9}$ The aim of this study was therefore to examine the subsite incidence of large bowel cancer by age, sex, socioeconomic status and time trends in a well defined French population.

\section{Methods}

The study included all cases of colorectal carcinoma reported to the digestive tract cancer registry of the department of Cote-d'Or (France). The cancer registry is population based and covers a population of 477952 according to the 1982 census. Among that population, $46 \%$ live in the urban centre of Dijon, $17 \%$ live in smaller towns, and $37 \%$ live in rural areas. Information was collected from pathology laboratories, university hospitals, local hospitals, surgeons, gastroenterologists, general practitioners, social security offices and death certificates. Because of the active cooperation of the medical profession in the department it was assumed that nearly all newly diagnosed cancers were registered.

The site was coded according to the International Classification of Diseases, ninth revision. ${ }^{10}$ Cancers of 
the appendix (153.5) were classified with cancer of the caecum because of small numbers (five cases). Cancers of the anal canal (154.3) were not included in the analysis because they have totally different histological and epidemiological features. Rectal cancers were separated into cancers of the lower rectum $(<8 \mathrm{~cm})$ and cancers of the upper rectum. For some calculations cancers of the large bowel were simply subdivided into three groups: (1) the right colon (including the caecum (153.4), appendix (153.5), ascending colon (153.6), hepatic flexure (153.0), and transverse colon (153.1)); (2), the left colon (including the splenic flexure $(153 \cdot 7)$, descending colon $(153 \cdot 2)$, and sigmoid (153.3)); (3), and the rectum (including the rectosigmoid junction (154.0), and rectal ampulla $(153 \cdot 1))$.

Socioeconomic status was determined for those cases reported between 1976 and 1980 by matching records with the 1975 population census. The latter included individual data on social class, type of housing (a good marker of income in France) and educational level. Census data were available for $85 \%$ of cancer cases. Additional information on social class was obtained from hospital records and a total of $94 \%$ of men were successfully classified according to social class. Social class determination for women was based on type of housing only because the majority were not employed outside the house and too few had education beyond the primary level.

The annual incidence rates were determined as the average of 8 years registration. The denominator was an estimate of the Cote d'Or population provided annually by the "Institut National de la Statistique et des Etudes Economiques" (INSEE). Age standardised incidence rates were calculated, using the world standard population. Age distribution for the different subsites were compared using a $\chi^{2}$ method. To compute rates for small subgroups (ie, for type of housing, social class and educational level) the so called indirect standardisation method (SIR) was applied. To describe the trend in cancer incidence, an exponential curve of the form $y=a^{b t}$ was fitted to the annual incidence rates by means of a regression technique. It allowed for a direct interpretation of the average annual percentage change. This annual percentage change is given together with the 95 per cent confidence interval $(\mathrm{CI})$.

\section{Results}

INCIDENCE BY AGE, SEX AND CANCER SITE

A total of 1782 large bowel cancers were diagnosed among Cote d'Or residents in the period 1976-1983. They represented $48.6 \%$ of digestive tract cancers. The age standardised incidence rate in men was 18.9/ 100000 for colon cancer and $18.4 / 100000$ for rectal cancer. The corresponding rates in women were $14 \cdot 2$ and $10 \cdot 2$.

The incidence of large bowel cancer by subsite and sex is shown in table 1 . In both sexes cancer of the rectal ampulla was the most common of the large bowel cancers followed by cancer of the sigmoid and cancer of the rectosigmoid junction. The incidence was low at the flexures and intermediate at the other subsites. There was little sex difference in subsite incidence from the caecum to the transverse colon. A male predominance was observed for the descending colon and the sigmoid. It was even more marked for the subsites of rectal cancer.

The mean age with standard error of the patients at the time of diagnosis was $69.4(11.5)$ years for men and $72.3(12.1)$ for women $(p<0.001)$. The mean age for each large bowel site is shown in table 1 . It was slightly greater for all localisations in females. Differences were significant for the caecum, the ascending colon, the hepatic flexure and the transverse colon. Age specific incidence rates for each subsite for both sexes computed by five year interval up to 80 are given in

Table 1 Mean age at diagnosis and incidence by sex and localisation for large bowel cancers

\begin{tabular}{|c|c|c|c|c|c|c|c|c|}
\hline & & \multicolumn{2}{|c|}{ Number of cases ${ }^{a}$} & \multicolumn{2}{|c|}{ Age at diagnosis ${ }^{b}$} & \multicolumn{3}{|c|}{ Age standardised rates ${ }^{c}$} \\
\hline & & Males & Females & Males & Females & Males & Females & Sex ratio \\
\hline $\begin{array}{l}153.4 \\
153.6 \\
153.0 \\
153.1 \\
153.7 \\
153.2 \\
153.3 \\
154.0 \\
154.1\end{array}$ & $\begin{array}{l}\text { Caecum } \\
\text { Ascending } \\
\text { Hepatic flexure } \\
\text { Transverse } \\
\text { Splenic flexure } \\
\text { Descending } \\
\text { Sigmoid } \\
\text { Rectosigmoid junction } \\
\text { Rectal ampulla }\end{array}$ & $\begin{array}{r}73 \\
42 \\
14 \\
38 \\
18 \\
28 \\
264 \\
164 \\
292\end{array}$ & $\begin{array}{r}101 \\
61 \\
23 \\
58 \\
17 \\
30 \\
237 \\
130 \\
185\end{array}$ & $\begin{array}{l}70 \cdot 1 \\
68 \cdot 5 \\
60 \cdot 7 \\
68 \cdot 3 \\
69 \cdot 7 \\
71 \cdot 5 \\
69 \cdot 3 \\
69 \cdot 7 \\
69 \cdot 6\end{array}$ & $\begin{array}{l}75 \cdot 9^{*} \\
75 \cdot 0 t^{*} \\
73 \cdot 1^{*} \\
74 \cdot 6^{*} \\
72 \cdot 9 \\
69 \cdot 1 \\
71 \cdot 3 \\
70 \cdot 7 \\
71 \cdot 9\end{array}$ & $\begin{array}{r}2.9 \\
1.7 \\
0.9 \\
1.5 \\
0.7 \\
1.1 \\
10 \cdot 4 \\
6.7 \\
11.4\end{array}$ & $\begin{array}{l}2 \cdot 3 \\
1 \cdot 4 \\
1 \cdot 0 \\
1 \cdot 3 \\
0 \cdot 5 \\
0 \cdot 9 \\
6 \cdot 8 \\
3 \cdot 7 \\
5 \cdot 2\end{array}$ & $\begin{array}{l}1 \cdot 3 \\
1.2 \\
0.9 \\
1 \cdot 2 \\
1.4 \\
1 \cdot 2 \\
1.5 \\
1.8 \\
2 \cdot 2\end{array}$ \\
\hline
\end{tabular}

${ }^{a}$ Subsite unknown for 2 men and 5 women; ${ }^{b}$ Mean, years; ${ }^{c}$ Incidence per 100,000

$* \mathrm{p}<0.05 ; \uparrow \mathrm{p}<0.01$ 

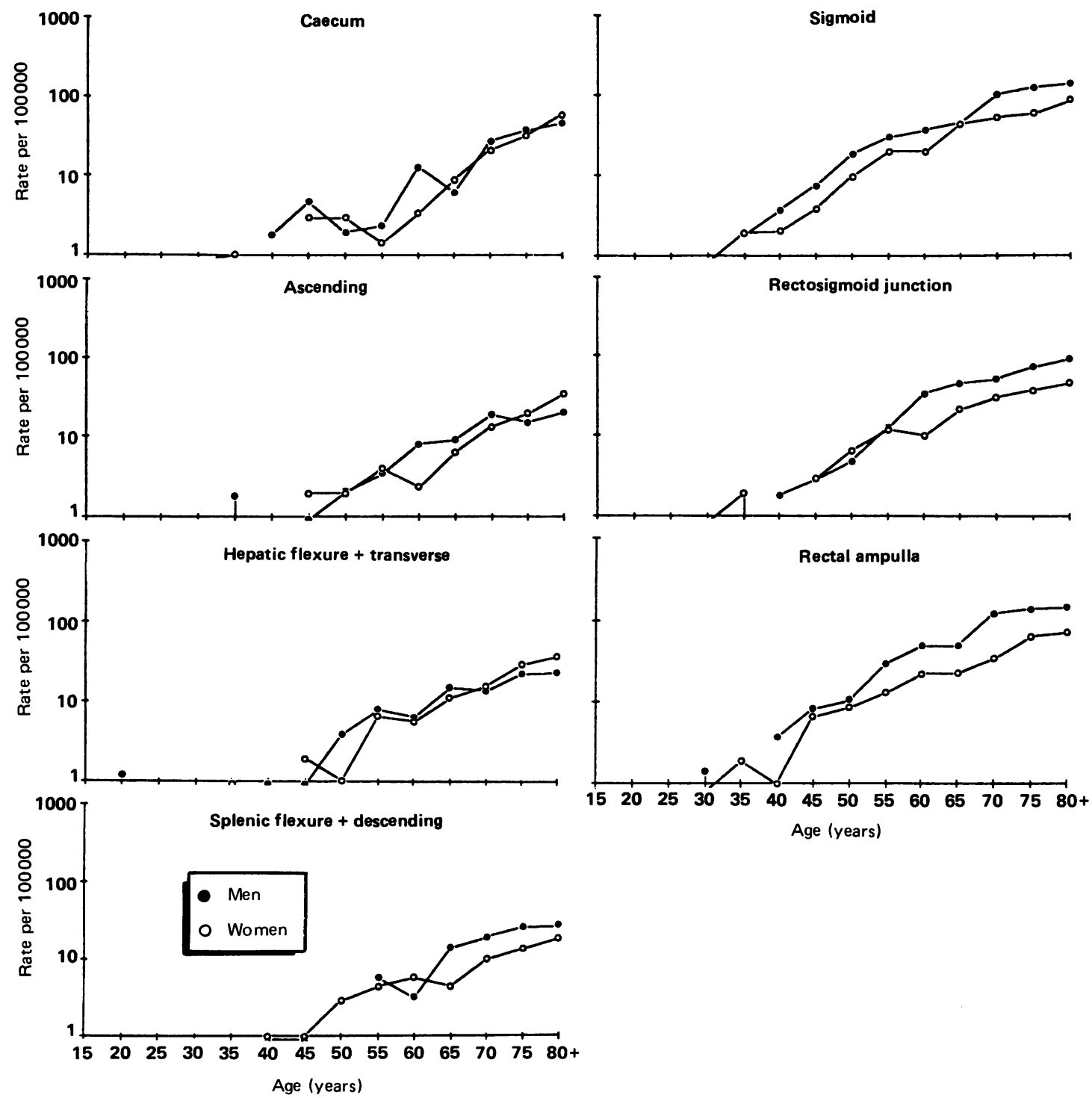

Age (years)

Fig 1 Sex and age specific incidence of colorectal cancer at various sites among Cote d'Or residents (1976-1983) (semilogarithmic scale).

fig 1. Comparing age specific incidence curves by sex for each subsite, cancer of the rectal ampulla and cancer of the the rectosigmoid junction showed similar characteristics: under age 50 , the age specific incidence rates were very similar in the two sexes, but among older individuals males had approximately twice the rates of females. For cancer of the sigmoid and cancer of the descending colon the male predominance was less marked and was present only in the group older than 65. Age specific incidence curves for cancers of the transverse, ascending colon and caecum were very similar in the two sexes. The pattern of age specific incidence rates was similar for each subsite among males. In females, however the pattern in left colon and rectal cancers of age specific incidence rates were similar to each 
Table 2 Incidence of large bowel cancers in Cote d'Or (1976-1983) by place of residence, subsite and sex. Age adjusted incidence rate per 100000 per annum

\begin{tabular}{|c|c|c|c|c|c|c|}
\hline & \multicolumn{3}{|l|}{ Males } & \multicolumn{3}{|c|}{ Females } \\
\hline & Urban & Rural & $U / R$ ratio & Urban & Rural & $U / R$ ratio \\
\hline $\begin{array}{l}\text { Right colon } \\
\text { Left colon } \\
\text { Rectum }\end{array}$ & $\begin{array}{r}7 \cdot 2 \\
13 \cdot 2 \\
17 \cdot 8\end{array}$ & $\begin{array}{r}6 \cdot 3 \\
10 \cdot 9 \\
18 \cdot 5\end{array}$ & $\begin{array}{l}1 \cdot 1 \\
1.2 \\
1.0\end{array}$ & $\begin{array}{l}5 \cdot 6 \\
8 \cdot 6 \\
9 \cdot 2\end{array}$ & $\begin{array}{l}6.0 \\
7.9 \\
8.6\end{array}$ & $\begin{array}{l}0.9 \\
1.1 \\
1.1\end{array}$ \\
\hline
\end{tabular}

Table 3 Standardised incidence ratios for large bowel cancers in males in Cote d'Or (1976-1980) by subsite, socioeconomic status and education

\begin{tabular}{lrcc}
\hline & $\begin{array}{c}\text { Right } \\
\text { colon }\end{array}$ & $\begin{array}{l}\text { Left } \\
\text { colon }\end{array}$ & Rectum \\
\hline Socioeconomic status & & & \\
$\quad$ High executives and middle & 106 & $153 \dagger$ & 111 \\
$\quad$ management & 95 & 136 & 93 \\
$\quad$ Self employed persons & 81 & 79 & $140 \dagger$ \\
$\quad$ Farmers & 107 & 88 & $59^{*}$ \\
$\quad$ Employers & 108 & 85 & 90 \\
$\quad$ Workers & 90 & 91 & 97 \\
Education & 119 & 104 & 108 \\
$\quad$ Primary & 90 & 133 & 96 \\
$\quad$ Secondary & & & \\
$\quad$ High School/University & & & \\
\hline p < 0.05; $\dagger$ p < 0.01 & &
\end{tabular}

other but markedly different from right colon cancers $(\mathrm{p}<0.001)$.

\section{URBAN-RURAL DIFFERENCES}

In men the risk of rectal cancer was similar in urban and rural areas. There was a slight urban predominance for right and left colon cancers (NS). In women the incidence rates were similar in urban and rural areas for all colorectal cancers (table 2).

\section{INCIDENCE BY SOCIOECONOMIC STATUS}

Large bowel incidence rates by social class for men are given in table 3 . Significantly higher rates were observed in high executives and middle management for left colon cancers, and in farmers for rectal cancers than in the other groups. No significant association was found with education.

Risk by type of housing was uniform for men in right colon cancer and rectal cancer. There was a clear association between type of housing and risk of left colon cancer in men, with a progressively increasing risk with increasing level of housing. There were few variations in incidence in women (table 4).

\section{TIME TRENDS}

Time trends in age adjusted incidence rates for the localisations of large bowel cancer are shown in fig 2 .
The mean annual increase with $95 \%$ CI was, for right colon cancer, $2 \cdot 5 \%(-9 \cdot 1,+14 \cdot 1)$ in men (NS) and $3 \cdot 1 \%(-1 \cdot 7,+7 \cdot 9)$ in women (NS). Left colon cancer incidence rates increased respectively by $5 \cdot 2 \%(+3.5$, $+6.9 ; \mathrm{p}<0.01)$, and $7.7 \%(+2.7,+12.5 ; \mathrm{p}<0.05)$, whereas rectal cancer rates decreased by $2 \cdot 7 \%(-2 \cdot 3$, $+7 \cdot 7 ; \mathrm{NS})$, and $5 \cdot 2 \%(-2 \cdot 2,-8 \cdot 2 ; \mathrm{p}<0.05)$.

\section{Discussion}

Large bowel cancer is separated by the International Classification of Diseases in two different entities: cancer of the colon and cancer of the rectum. ${ }^{10}$ Descriptive epidemiological data confirm that cancer of the colon and of the rectum should be considered separately in aetiological inquiries. Although there is a strong correlation between the incidence of both colonic and rectal cancers, there is not always a strict parallel. The variation in incidence throughout the world appears to be somewhat less marked for rectal cancer than for colonic cancer. The highest incidence of colonic cancer is found in the USA, whereas the regions at highest risk for rectal cancer are situated in Western Europe. ${ }^{2}$ In the high risk populations of North America and Australasia the colon to rectum ratio for age adjusted incidence rates is between 1.5 and 2.0 in males, and between 2.0 and 2.5 in females. These ratios are generally lower in the high risk populations of Western Europe. They are near to 1.0 in men and 1.5 in women. Though tumours located near the rectosigmoid junction could be classified differently according to the countries, this fact should account for little in the overall distribution. The different subsites display similar epidemiological features, and in particular similar variations in the sex ratio are observed in all these high risk regions. Further evidence that colon and rectum should be considered separately comes from studies of racial or religious groups. In Hawaii or in San Francisco ${ }^{2}$ important racial differences are observed in incidence rates for colonic cancer. They are much smaller for rectal cancer. In an incidence study in Denmark, Seventh Day Adventists had a significantly lower risk of colonic cancer, whereas the risk of rectal cancer was 
Table 4 Standardised incidence ratio for large bowel cancers in Cote d'Or (1976-1980) by subsite type of housing and sex

\begin{tabular}{|c|c|c|c|c|c|c|}
\hline & \multicolumn{2}{|c|}{ Right colon } & \multicolumn{2}{|c|}{ Left colon } & \multicolumn{2}{|c|}{ Rectum } \\
\hline & Males & Females & Males & Females & Males & Females \\
\hline $\begin{array}{l}\text { Substandard housing } \\
\text { Housing with sanitary facilities } \\
\text { Housing with bathroom } \\
\text { Housing with bathroom and central heating }\end{array}$ & $\begin{array}{l}101 \\
100 \\
110 \\
108\end{array}$ & $\begin{array}{c}92 \\
153^{*} \\
72 \\
108\end{array}$ & $\begin{array}{l}63 \\
107 \\
108 \\
141+\end{array}$ & $\begin{array}{c}97 \\
148^{*} \\
70 \\
104\end{array}$ & $\begin{array}{l}103 \\
103 \\
117 \\
101\end{array}$ & $\begin{array}{r}116 \\
61 \\
93 \\
110\end{array}$ \\
\hline
\end{tabular}

* $\mathrm{p}<0.05+\mathrm{p}<0.01$
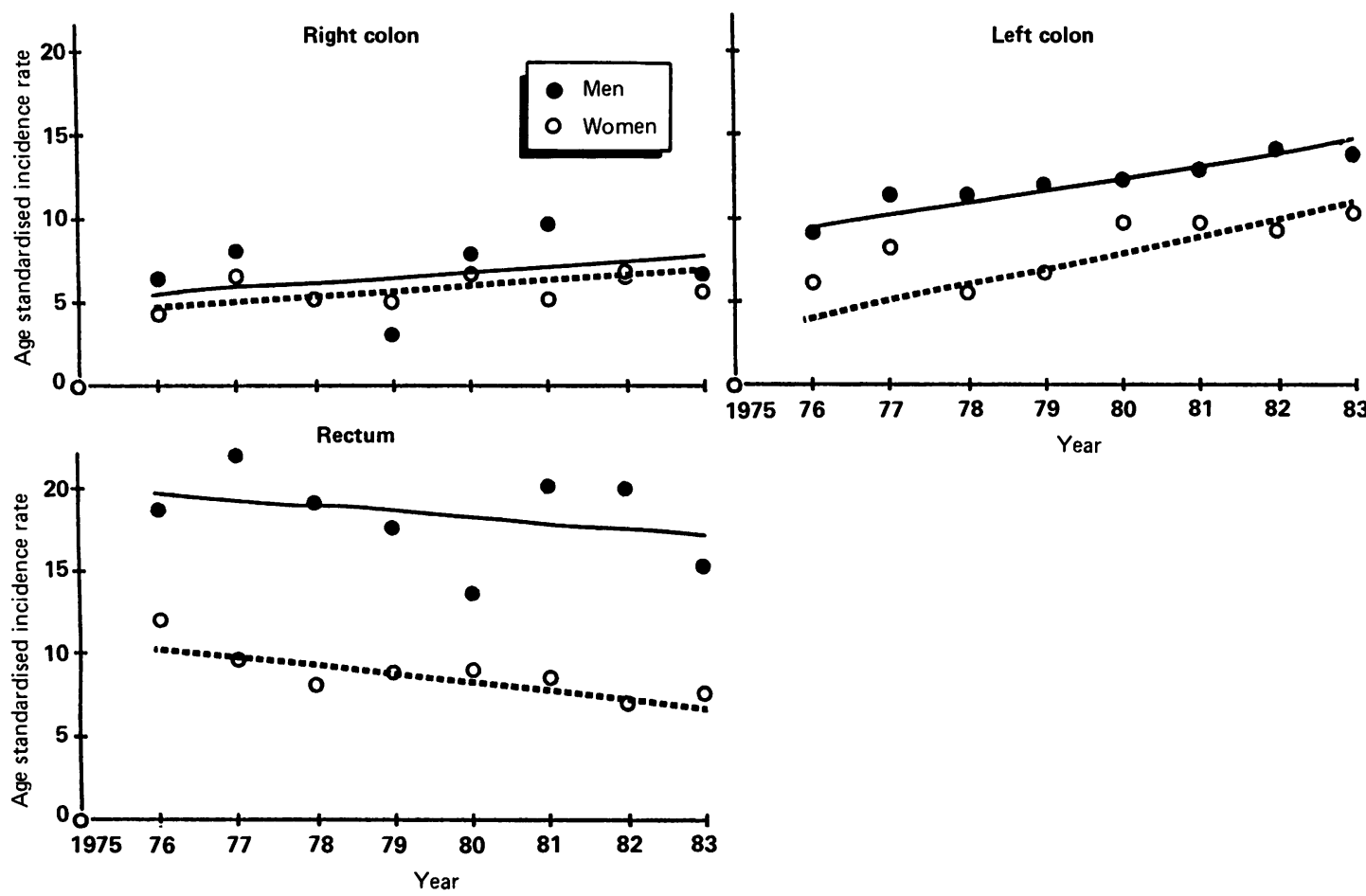

Fig 2 Trends in age adjusted incidence rates for colorectal cancer in Cote d'Or by site and sex (regression line of cancer site incidence)

not significantly different from that of the general population. ${ }^{11}$ Like for most neoplasms of an epithelial origin, cancer incidence in the various parts of the large bowel increase exponentially with age. The reported data from Cote d'Or show that the incidence distribution by age and sex varies for the different anatomic parts of the large bowel. Similar data have been reported from the Danish Cancer Registry for the period 1978 to $1980 .{ }^{12}$ Data on urban-rural distribution of large bowel cancers are limited to the rough distinction between colonic and rectal cancer. For rectal cancer the urban $v$ rural incidence ratio is about 1 . For colonic cancer incidence rates tend to be slightly higher in urban areas than in rural areas. ${ }^{2}$ Our data indicate that the urban excess is more pronounced for the left colon than for the right colon.

In the high risk populations for large bowel cancer there is little variation in the incidence between various socioeconomic groups. Mortality data from England and Wales indicate a greater risk of sigmoid cancer in the upper social classes in males, whereas the lower class had a higher risk of rectal cancer. ${ }^{5}$ The data from Cote d'Or suggest that the higher risk in the upper socioeconomic groups would be limited to left colon 
cancer. No differences among social classes are observed for right colon cancer. For rectal cancer the higher risk observed among farmers confirms similar findings from Finland. ${ }^{4}$

Some data on the chronological changes in subsite specific incidence rate of large bowel cancer are available. Trends in incidence vary from one region to another. In Connecticut there was an increase in rates for caecum-ascending and sigmoid cancers. Little change occurred for cancers of other sites. ${ }^{8}$ In Rochester (Minnesota) there was an increase in the incidence of cancer of the caecum, and a fall in the incidence of cancer of the sigmoid. ${ }^{6}$ Similar trends were observed from Canada. ${ }^{9}$ In Hawaii the site specific time trends revealed that the greatest increase occurred in rectosigmoid cancer followed by cancer of the sigmoid, and cancer of the right colon. ${ }^{7}$ In Cote d'Or there was a rise in right and left colon cancer while there was a decrease in rectal cancer incidence. These different time trends in the subsite distribution of large bowel cancer again suggest partly different aetiologies.

The differences in the epidemiology of cancers of the right colon, left colon and rectum suggest that aetiological factors for cancers of these three parts of the large bowel may be different. The different patterns of male and female incidence rates from the present study support the hypothesis that there are differences between the sexes in the aetiology of the disease. This difference between the sexes must be accounted for in epidemiological studies. Our study confirms fragmentary information from other population based studies on the importance of distinguishing three different subsites in colorectal cancers for further analytical epidemiological studies.

Address for correspondence: Professor J. Faivre, Faculté de Médecine, 7 Boulevard Jeanne d'Arc, 21033 Dijon Cédex, France.

\section{References}

${ }^{1}$ De Jong UW, Day NE, Muir CS et al. The distribution of cancer within the large bowel. Int J Cancer 1972; 10: 463-77.

${ }^{2}$ Waterhouse J, Muir C, Shanmugaratnam K, Powell J. Cancer incidence in five continents. Vol 4. Lyon: IARC Scientific Publications No 42, 1982.

${ }^{3}$ Lynch HT, Guirgis H, Lynch J, Brodkey FD, Magee H. Cancer of the colon: socioeconomic variables in a community. Am J Epidemiol 1975; 102: 119-27.

${ }^{4}$ Nayha S. Social group and mortality in Finland. Br J Prev Soc Med 1977; 31: 231-7.

${ }^{5}$ Office of Population Censuses and Surveys, occupational mortality. The Registrar General's decennial supplement for England and Wales, 1970-1972. London: Her Majesty's Stationery Office, 1978.

${ }^{6}$ Beart RW, Melton LJ, Maruta M, Dockerty MB, Frydenberg HB, O'Fallow WM. Trends in right and left-sided colon cancer. Dis Colon Rect 1983; 26: 393-8.

${ }^{7}$ Nomura AM, Kolonel LN, Hinds MW. Trends in the anatomical distribution of colorectal carcinoma in Hawaii, 1960-1978. Dig Dis Sci 1981; 26: 11.16-20.

${ }^{8}$ Snyder DN, Heston JF, Meigs JW, Flannery JT. Changes in site distribution of colorectal carcinoma in Connecticut, 1940-1973. Am J Dig Dis 1977; 22: 791-7.

9 Vobecky J, Leduc C, Devroede G. Sex differences in the changing anatomic distribution of colorectal carcinoma. Cancer 1984; 54: 3065-9.

${ }^{10}$ World Health Organization. Manual of the International Statistical Classification of Diseases, Injuries and causes of death, Ninth revision. Geneva: WHO, 1977.

11 Jensen OM. Cancer risk among Danish male Seventh Day Adventists and other temperance society members. J Natl Cancer Inst 1983; 70: 1011-4.

12 Jensen OM. The epidemiological of large bowel cancer. In: Reddy BS, Cohen LA eds. Diet, nutrition and cancer: $a$ critical evaluation. Boca Raton: CRC Press, 1987: 27-45.

Accepted for publication April 1989 